\title{
Metastatic cervical cancer treated with paclitaxel, ifosfamide and cisplatin (TIP), followed by local treatment and long-term follow up: case series
}

G. Zibetti Dal Molinn ${ }^{1}$, M. Martello Cristófalo ${ }^{2}$, L. Gomes ${ }^{1}$, C.L. Borrelli ${ }^{3}$, R.M.A. Pereira ${ }^{4}$, J.C. Sadalla ${ }^{5}$, F.C. Maluf ${ }^{1}$ ${ }^{1}$ Beneficência Portuguesa de São Paulo ${ }^{2}$ Faculdade de Ciências Médicas da Santa Casa de São Paulo ${ }^{3}$ Heliópolis Hospital ${ }^{4}$ Centro de endometriose e cirurgia ginecológica minimamente invasiva do hospital Santa Joana ${ }^{5}$ Sao Paulo Cancer Institute.

\section{OBJECTIVE}

Cervical cancer is a major cause of death by gynecological tumors worldwide. Therapeutic options for cervical cancer are limited in patients with recurrent or metastatic disease after platinum-based chemoradiotherapy or local therapy. ${ }^{1}$

\section{METHODS}

To report five cases of patients with metastatic cervical cancer treated with TIP followed by local treatment associated with long-term complete remission.

\section{CASE REPORT}

Patients age range from to 26 to 53 years old and had no comorbidities. Regarding histology, two of them were diagnosed with adenocarcinoma, one with squamous carcinoma and two with adenosquamous. Regarding staging, two patients were IB1, one IB2 and two IV. The main sites of metastasis were pelvic, paraortic and cervical lymph nodes, lung and ovarian bilaterally. No women underwent radiotherapy previously and three patients had surgery at diagnosis. Four patients completed six cycles and one finished four cycles of TIP. All patients had good tolerance to chemotherapy, without grade 3 or 4 toxicities. As local treatment, three patients underwent chemoradiotherapy, one was submitted to isolated radiotherapy and one to surgery. They are in complete remission between 24 and 120 months.

\section{CONCLUSION}

Systemic chemotherapy with TIP followed by salvage focal treatment is a promising therapeutic approach in selected patients, particularly in younger patients, without comorbidities, good performance status, low metastatic tumor burden, and with an objective response to chemotherapy. ${ }^{2}$

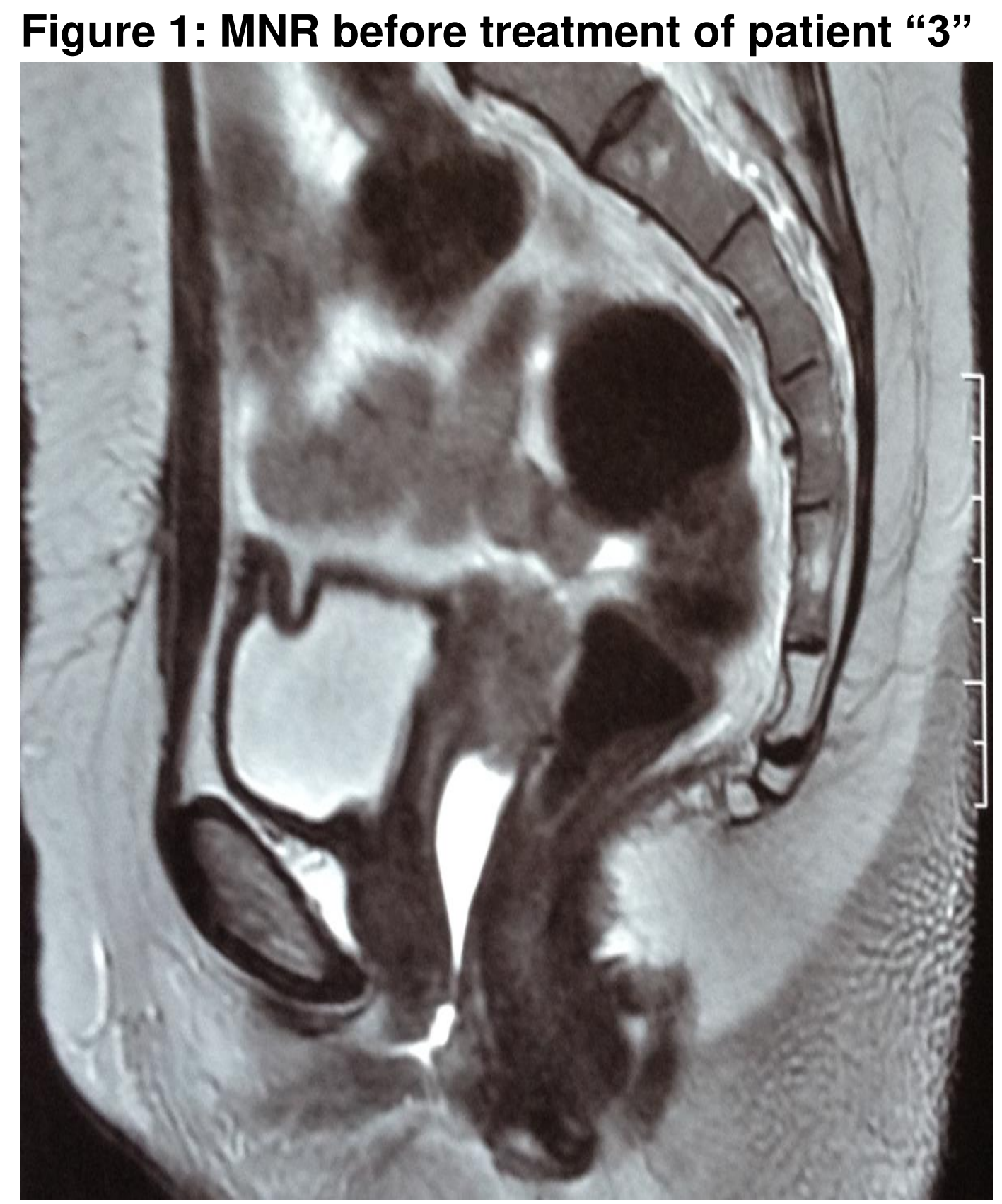

Table 1: Patients features analysed

\begin{tabular}{|ccccc|}
\hline ID & Histology & $\begin{array}{c}\text { TIP } \\
\text { cycles }\end{array}$ & Local treatment & $\begin{array}{c}\text { Months of } \\
\text { remission }\end{array}$ \\
\hline $\mathbf{1}$ & Adenocarcinoma & 6 & Lymph node RT & 55 \\
$\mathbf{3}$ & Adenosquamous & 6 & Lymph node and lung RT & 58 \\
$\mathbf{4}$ & Squamous cells & 6 & Surgery & 24 \\
5 & Adenocarcinoma & 6 & Lymph node RT & 86 \\
\hline
\end{tabular}

1. Dimopoulos MA, Papadimitriou CA et al. Combination of Ifosfamide, Paclitaxel, and Cisplatin for the treatment of metastatic and recurrent carcinoma of the uterine cervix: A Phase II Study of the Hellenic Cooperative Oncology Group. Gynecologic Oncology 2002; 85: 476-82.

2. Mountzios G, Dimopoulos MA et al. Randomized multicenter phase II trial of cisplatin and ifosfamide with or without paclitaxel in recurrent or metastatic carcinoma of the uterine cervix: a Hellenic Cooperative Oncology Group (HeCOG) study. Annals of Oncology 2009; 20: 1362-68. 